\title{
A Study to Compare the Effect of Ankle Exercises on Balance Vs. Ankle Exercises with Visual Feedback on Balance in Stroke Subjects
}

\section{Christina Kurien* and Prem Kumar}

Department of Physiotherapy, Kempegowda Institute of Medical Sciences Hospital and Research Centre, Bangalore, India

\begin{abstract}
Objective: The aim of this study was to compare the effectiveness of ankle exercises on balance vs. ankle exercises with visual feedback on balance in stroke subjects.

Subjects and Methods: In this study, 30 stroke patients were randomly and equally assigned. They performed ankle exercises for $1 \mathrm{~h}$, five times per week for three weeks. The patients balance ability was measured using Berg Balance Scale (BBS), Timed Up and Go test (TUG) before and after the exercises to compare the effect of ankle exercises. The Stroke Specific Quality of Life (SSQOL) was also used before and after the exercises.

Results: In this study the between group mean difference of BBS was $4 \pm 3.82$, the between group mean difference of TUG was $3.2 \pm 0.72$ and between group mean difference of SSQOL was $7.8 \pm 2.22$. The Baseline comparability was analysed using independent $t$-test and level of significance is $p<0.05$. This showed that patients in both groups improved significantly following the intervention and the patients treated with ankle exercises with visual feedback on balance had significant improvement in comparison to the patients treated with ankle exercises.
\end{abstract}

Conclusion: Ankle exercises with visual feedback had a positive effect on stroke patients to improve balance.

Keywords: Stroke; Balance; Ankle exercises; Visual feedback

\section{Introduction}

Stroke or brain attack is the sudden loss of neurological function caused by an interruption of the blood flow to the brain. The term Cerebro-vascular Accident (CVA) is used interchangeably with stroke to refer to the vascular conditions of the brain. To be classified as stroke, neurological deficits must persist for at least $24 \mathrm{~h}$. Stroke was the second most frequent cause of death worldwide in 2012, accounting for 6.7 million deaths [1]. Stroke is the number one preventable cause of permanent disability. Following stroke, patients lose functions of the motor, sensory and higher brain cognitive functions to various degrees which leads to diminished balance and they tend to put a smaller weight load on the paretic leg when in the standing position and this results in asymmetric posture, more posture sway, impaired weightshifting ability and decreased stability which in turn negatively affects their activities of daily living, gait, and movement [1-5].

Balance is the condition in which all the forces are acting on the body are balanced such that the Center of Mass (COM) is within the stability limits, the boundaries of the Base of Support (BOS). Postural control and balance are required components for walking and mobility after stroke. Patients with stroke show a pattern of increased postural sway during quiet standing due to motor, sensory, and cognitive impairments, which increases the risk of falls, as well as limits their ability to independently perform daily life activities [6,7].

Ankle joint strategies are important for gaits and functional activities. An ankle joint strategy is one in which the balance is maintained through a little movement with appropriately four actions that occur at the ankle joint; dorsiflexion, plantar flexion, inversion, and eversion. The ankle joint is important for the balancing strategy of the body. During walking, the ankle joint absorbs the impact of the ground reaction force, supports body weight, and propels the lower limb. Primary functions of the ankle joint are the provision of balance control against postural disturbance, absorption of shock during gait, and movement of lower extremity [8-10].

Visual feedback is a method which uses an optical illusion in which the movement of the paralyzed limbs appears to be normal through the reflection in a mirror of the movements of the non-paretic limb. Based on the neuroplasticity principle, this is one method used to treat patients with cerebral nerve damage. Visual feedback training using a mirror is a method that can lead to improvements in postural control by providing feedback on induced movements through a reflection of the body image in the mirror $[7,11]$.

The Stroke Specific Quality Of Life Scale (SS-QOL) is a self-report questionnaire consisting of 49 items in the 12 domains of energy, family roles, language, mobility, mood, personality, self-care, social roles, thinking, upper extremity function, vision, and work/productivity. The purpose of the study was to compare the effectiveness of ankle exercises on balance versus ankle exercises with visual feedback on balance in stroke subjects $[12,13]$.

\section{Subjects and Methods}

The subjects of this study were 30 stroke patients (15 in each group) who were hospitalized at or visited Kempegowda Institute of Medical Science Hospital and Research Center, Bangalore, Karnataka, India. All subjects consented to participate in this study. The subjects were randomly and equally assigned to both the groups. The inclusion criteria were as follows:

1. Hemiplegia caused by a stroke within 45 days;

2. A score of 24 points or higher of the Mini-Mental State Examination;

*Corresponding author: Christina Kurien, Department of Physiotherapy, Kempegowda Institute of Medical Sciences Hospital and Research Centre, Bangalore-560004, India, Tel: +0096598820951; E-mail: christmasgirl92@gmail.com

Received: June 26, 2018; Accepted: November 12, 2018; Published: November 16,2018

Citation: Kurien C, Kumar P (2018) A Study to Compare the Effect of Ankle Exercises on Balance Vs. Ankle Exercises with Visual Feedback on Balance in Stroke Subjects. Physiother Rehabil 3: 163. doi: 10.4172/2573-0312.1000163

Copyright: $\odot 2018$ Kurien C, et al. This is an open-access article distributed under the terms of the Creative Commons Attribution License, which permits unrestricted use, distribution, and reproduction in any medium, provided the original author and source are credited. 
Citation: Kurien C, Kumar P (2018) A Study to Compare the Effect of Ankle Exercises on Balance Vs. Ankle Exercises with Visual Feedback on Balance in Stroke Subjects. Physiother Rehabil 3: 163. doi: 10.4172/2573-0312.1000163

Page 2 of 3

\begin{tabular}{|c|c|c|c|}
\hline \multirow{2}{*}{ Measures } & Group A (n=15) & Group B (n=15) & \multirow{2}{*}{ P-value } \\
\cline { 2 - 3 } & Mean \pm SD & Mean $\mathbf{\text { SD }}$ & \\
\hline Age & $58.27 \pm 12.83$ & $49.4 \pm 11.83$ & 0.059 \\
\hline Gender M [(\%): $\mathbf{F ( \% ) ] ~}$ & $11(73 \%): 4(27 \%)$ & $10(67 \%): 5(33 \%)$ & NS \\
\hline BBS & $34.93 \pm 5.84$ & $43.93 \pm 12.13$ & 0.015 \\
\hline TUG & $23.2 \pm 6.93$ & $17.73 \pm 4.79$ & 0.018 \\
\hline SSQOL & $111.13 \pm 16.08$ & $134.20 \pm 25.32$ & 0.006 \\
\hline
\end{tabular}

Table 1: Demographic characteristics and outcome variables at baseline.

3. Brunnstrom recovery stage of two or three;

4. The ability to stand up independently;

5. No musculoskeletal disorders or degenerative disease affecting balance in standing posture;

6. Subjects who have given the written informed consent. The Ethics Committee of Kempegowda Institute of Medical Science Hospital and Research Center. The characteristics of the subjects are shown in Table 1.

All the baseline data was collected-demographic details (name, age, gender, hand dominance, side affected and duration of stroke). Subjects were ruled out for perceptual and cognitive deficits like hemi spatial neglect; attention and memory deficits orthopedic, vestibular, and other neurological conditions. Both the group underwent tests, such as TUG test, BBS Test, and SSQOL, and their training comprised of ankle exercises for one hour, five times per week for three weeks. The ankle exercises consisted of exercises in standing and sitting and it was preceded by a warm-up exercise and followed by a cool-down exercise. The whole process was observed and guided by a therapist. The ankle exercise program were:

1. Sit to stand;

2. Slowly raise and lower both heels;

3. Standing with 2 feet support posture;

4. Unaffected foot on floor bending and extending knee of affected foot on balance Board.

The data collected in the present study were analyzed using SPSS 18.0, and R environment ver.3.2.2. Descriptive and inferential-statistical analysis has been carried out in the present study. Results on continuous measurements are presented on Mean \pm SD (Min-Max) and results on categorical measurements are presented in number (\%). Significance is assessed at $5 \%$ level of significance. The following assumptions on data are made.

\section{Assumptions}

\section{Dependent variables should be normally distributed.}

2. Samples drawn from the population should be random.

Cases of the samples should be independent. Student $t$ test (two tailed, independent) has been used to find the significance of study parameters on continuous scale between two groups (Inter group analysis) on metric parameters. Levene's test for homogeneity of variance has been performed to assess the homogeneity of variance. Student $t$ test (two tailed, dependent) has been used to find the significance of study parameters on continuous scale within each group. Chi-square/Fisher Exact test has been used to find the significance of study parameters on categorical scale between two or more groups, Non-parametric setting for Qualitative data analysis. Fisher Exact test used when cell samples are very small.

\section{Results}

Tables 2,3 and 4 shows values of pre-test and post-test of both the groups. Changes in TUG, BBS and SSQOL between pre-test and posttest were statistically significant in both groups.

In this study it was found that there was a mean difference of 2.4 \pm 1.64 points and $6.4 \pm 5.55$ points within Group A and Group B respectively with a between group mean difference of $4 \pm 3.82$ points with p-value being 0.009. This showed that patients in both Group A and Group B improved significantly following the intervention and the Group B had significant improvements in comparison to the Group A.

In this study it was found that there was a mean difference of -1.54 \pm 0.99 points and $-4.74 \pm 1.71$ points within Group A and Group B respectively with a between group mean difference of $3.2 \pm 0.72$ points with p-value being $<0.001$. This showed that patients in both Group A and Group B improved significantly following the intervention and the Group B had significant improvements in comparison to the Group A.

In this study it was found that there was a mean difference of $3.2 \pm 1.74$ points and $11 \pm 3.97$ points within Group A and Group B respectively with a between group mean difference of $7.8 \pm 2.22$ points with p-value being $<0.001$. This showed that patients in both Group A and Group B improved significantly following the intervention and the Group B had significant improvements in comparison to the Group A.

\section{Discussion}

Stroke or brain attack is the sudden loss of neurological function caused by an interruption of the blood flow to the brain. The term Cerebro-vascular Accident (CVA) is used interchangeably with stroke to refer to the vascular conditions of the brain. To be classified as stroke, neurological deficits must persist for at least $24 \mathrm{~h}$ [1]

The aim of the study was to find the effectiveness of ankle exercises on balance when compared to ankle exercises with visual feedback on balance in stroke subjects. Ankle exercises with visual feedback showed better improvement in balance and proprioception when compared to ankle exercises without visual feedback.

\begin{tabular}{|c|c|c|c|c|}
\hline \multirow{2}{*}{$\begin{array}{c}\text { Outcome } \\
\text { measures }\end{array}$} & $\begin{array}{c}\text { Pre- } \\
\text { Intervention }\end{array}$ & $\begin{array}{c}\text { Post- } \\
\text { Intervention }\end{array}$ & $\begin{array}{c}\text { Intervention } \\
\text { Difference }\end{array}$ & \multirow{2}{*}{ P-value } \\
\cline { 2 - 5 } & Mean \pm SD & Mean \pm SD & (Mean \pm SD) & \\
\hline BBS & $34.93 \pm 5.84$ & $37.33 \pm 6.30$ & $2.4 \pm 1.64$ & $<0.001$ \\
\hline TUG & $23.2 \pm 6.93$ & $21.67 \pm 6.87$ & $-1.54 \pm 0.99$ & $<0.001$ \\
\hline SSQOL & $111.13 \pm 16.08$ & $114.33 \pm 16.15$ & $3.2 \pm 1.74$ & $<0.001$ \\
\hline
\end{tabular}

Table 2: Within group comparison of BBS, TUG and SSQOL in Group A.

\begin{tabular}{|c|c|c|c|c|}
\hline \multirow{2}{*}{$\begin{array}{c}\text { Outcome } \\
\text { measures }\end{array}$} & $\begin{array}{c}\text { Pre- } \\
\text { Intervention }\end{array}$ & $\begin{array}{c}\text { Post- } \\
\text { Intervention }\end{array}$ & $\begin{array}{c}\text { Intervention } \\
\text { Difference }\end{array}$ & \multirow{2}{*}{ P-value } \\
\cline { 2 - 5 } & Mean \pm SD & Mean \pm SD & (Mean \pm SD) & \\
\hline BBS & $43.93 \pm 12.13$ & $50.33 \pm 6.91$ & $6.4 \pm 5.55$ & 0.001 \\
\hline TUG & $17.73 \pm 4.79$ & $13 \pm 3.49$ & $-4.74 \pm 1.71$ & $<0.001$ \\
\hline SSQOL & $134.20 \pm 25.31$ & $145.20 \pm 23.81$ & $11 \pm 3.97$ & $<0.001$ \\
\hline
\end{tabular}

Table 3: Within group comparison of BBS, TUG and SSQOL in Group B.

\begin{tabular}{|c|c|c|c|c|}
\hline \multirow{2}{*}{ Outcome measures } & Mean difference & \multicolumn{2}{|c|}{$95 \% \mathbf{C l}$} & \multirow{2}{*}{ P-value } \\
\cline { 2 - 4 } & (Mean \pm SD) & Lower & Upper & \\
\hline BBS & $4 \pm 3.82$ & 1.12 & 7.15 & 0.009 \\
\hline TUG & $3.2 \pm 0.72$ & -4.25 & -2.16 & $<0.001$ \\
\hline SSQOL & $7.8 \pm 2.22$ & 5.51 & 10.09 & $<0.001$ \\
\hline
\end{tabular}

Table 4: Between group comparison of BBS, TUG and SSQOL. 
Following stroke, patients lose functions of motor, sensory and higher cognitive functions to various degrees that leads to decreased balance ability and tend to put a smaller weight load on the paretic leg when in the standing position and this results in posture sway, asymmetric weight distribution, impaired weight-shifting ability and decreased stability which in turn negatively affects their activities of daily living, gait, and movement [1-5]. The impact of ankle exercises on balance and ankle exercises with visual feedback on balance for the above mentioned disabilities were analysed and clinically relevant outcome measures were chosen for the same. BBS and TUG were used to see the effect on balance, SSQOL was used to measure quality of life in stroke subjects.

Study by Chen. et al [14] showed significant improvements in dynamic balance function of patients in the visual feedback training group when compared to the control group. The results showed that balance training was beneficial for patients after hemiplegic stroke.

Study by Persson et al. [15] indicate that the timed up \& go demonstrates ability to detect change in mobility over time in patients with stroke, a statistically significant improvement in TUG time from the $1^{\text {st }}$ week to 3 months after stroke was found. Thus, the result justifies the use of TUG in stroke rehabilitation.

In this study it was found that there was a mean difference of $3.2 \pm 1.74$ points and $11 \pm 3.97$ points within Group A and Group B respectively with a between group mean difference of $7.8 \pm 2.22$ points with p-value being $<0.001$. This showed that patients in both Group A and Group B improved significantly following the intervention and the Group B had significant improvements in comparison to the Group A.

In this study, the intervention focused on ankle exercises such as dorsiflexion, plantar flexion, raising of toes, raising of heels, shifting weight to the left and right side, shifting weight backward and forward, bending and extending knee and sit to stand. The exercises performed by the patients were carried out in front of a mirror while sitting, standing on a stable surface and on a balance board which indicated improvement in balance among the stroke patients which was significantly proved by the statistical analysis.

The study was carried out on small sample size. No long term follow up was carried out to assess whether patients retained the gained improvement after 3 weeks of the intervention. Therefore, more research on large groups and follow up about the improvement should be conducted.

This shows that patients after stroke had a better quality of life along with activities of daily living when their balance performance improved by ankle exercises with visual feedback.

\section{Conclusion}

Following stroke, patients lose functions of motor, sensory and higher cognitive functions to various degrees that leads to decreased balance ability and tend to put a smaller weight load on the paretic leg when in the standing position and this results in posture sway, asymmetric weight distribution, impaired weight-shifting ability and decreased stability which in turn negatively affects their activities of daily living, gait, and movement. The impact of ankle exercises on balance and ankle exercises with visual feedback on balance for the above mentioned disabilities were analyzed and clinically relevant outcome measures were chosen for the same.

This was a comparative study which included 30 subjects, 15 in each group conducted for a period of 12 months at Kempegowda Institute of Physiotherapy, Bangalore. The frequency of the study was 5 sessions of an hour per week for 3 weeks. Prior to exercise intervention, BBS, TUG and SSQOL scales was measured and recorded on day 1 and after 3 weeks to appreciate the improvement. Group A was treated with ankle exercises and Group B was treated with ankle exercises with visual feedback. The intervention focused on ankle exercises such as dorsiflexion, plantarflexion, raising of toes, raising of heels and sit to stand. The exercises performed by the patients were carried out in front of a mirror while sitting, standing on a stable surface and on a balance board.

Subjects treated with ankle exercises with visual feedback on balance (Group B) showed better improvement when compared to subjects treated with ankle exercises (Group A) after the respective intervention. The result shows BBS, TUG and SSQOL significantly improved in both the groups.

The results observed in this study concluded that Ankle exercises with Visual feedback was effective in treating stroke subjects which was proved by statistical analysis, that the post intervention result of Group $\mathrm{B}$ was better when compared to Group A.

\section{References}

1. Susan B O'Sullivan, Schmitz TJ (2007) Physical Rehabilitation. (5thedn) Philadelphia: Jaypee Brothers, pp: 1383.

2. Steiner T, Mendoza G, De Georgia M, Schellinger P, Holle R, et al. (1997) Prognosis of Stroke Patients Requiring Mechanical Ventilation in a Neurological Critical Care Unit. Stroke 28: 711-715.

3. Manorenj S, Inturi S, Jyotsna B, Savya VS, Areli D, et al. (2016) Prevalence, pattern, risk factors and outcome of stroke in women: a clinical study of 100 cases from a tertiary care center in South India. Int J Res Med Sci 4: 23882393.

4. Kamalakannan S, Gudlavalleti ASV, Gudlavalleti VSM, Goenka S, Kuper H (2017) Incidence and prevalence of stroke-A systematic review. Indian J Med Res 146: 175-185

5. Pandian JD, Sudhan $P(2013)$ Stroke epidemiology and stroke care services in India. J Stroke 15: 128-134

6. Ordahan B, Karahan AY, Basaran A, Turkoglu G, Kucuksarac S, et al. (2015) Impact of exercises administered to stroke patients with balance trainer on rehabilitation results: a randomized controlled study. Hippokratia, 19: 125-130.

7. In ST, Cha YR, Jung JH, Jung KS (2016) Effects of visual feedback with a mirror on balance ability in patients with stroke. J Phys Ther Sci 28: 181-185.

8. Park HK, Lim JY, Kim TH (2016) The effects of ankle strategy exercises on unstable surfaces on dynamic balance and changes in the COP. J Phys Ther Sci 28: 456-459.

9. Kim SS, Lee HJ, You YY (2015) Effects of ankle strengthening exercise combined with motor imagery training on the timed up and go test score and weight bearing ratio in stroke patients. J Phys Ther Sci 27: 2303-2305.

10. Park YH, Kim YM, Lee BH (2013) An ankle proprioceptive control program improves balance, gait ability of chronic stroke patients. J Phys Ther Sci 25 1321-1324.

11. Jeon SN, Choi JJ (2015) The effects of ankle joint strategy exercises with and without visual feedback on the dynamic balance of stroke patients. J Phys Ther Sci 27: 2515-2518.

12. Lin KC, Fu T, Wu CY, Hsieh CJ (2011) Assessing the stroke-specific quality of life for outcome measurement in stroke rehabilitation: minimal detectable change and clinically important difference. Health Qual Life Outcomes 9: 5.

13. Krančiukaitè D, Rastenytè D (2006) Measurement of quality of life in stroke patients. Medicina 42

14. Chen IC, Cheng PT, Chen C, Chen SC, Chung CY, et al. (2002) Effects of balance training on hemiplegic stroke patients. Chang Gung Med J 25: 583-590.

15. Persson CU, Danielsson A, Sunnerhagen KS, Ekman AG, Hansson PO (2014) Timed up \& go as a measure for longitudinal change in mobility after strokepostural stroke study in Gothenburg (POSTGOT). J Neuroeng Rehabil 11: 83. 